DOI: $10.1515 /$ hssr -2016-0002

\title{
Vulnerability at the Heart of the Ethical Implications of New Biotechnologies
}

Pascal Salin*

Paris-Dauphine University, France

\begin{abstract}
Human activities have become more and more internationalized in the course of recent decades and globalization is a major fact of our time. Latest changes in economics, politics and technology are not always well understood and well accepted. Many people consider globalization as detrimental since it is assumed that it destroys jobs in developed countries because of the alleged competition from low-wage countries, and that it could lead to a "standardization" of lifestyles and even cultures. Some wrongly believe that given these dangers, the economic globalization should be accompanied by globalized economic policies, that actually curb freedom of trade. Our article clarifies the meaning of freedom of trade and competition, underlines the fact that there are two radically opposed approaches to integration and discusses, finally, accomplishments or projects concerning taxation, regulations, monetary integration and banking union.
\end{abstract}

Keywords

Economic Globalization, Trade, Competition, Integration

It is undeniable that human activities have become more and more internationalized in the course of recent decades and globalization is a major fact of our time. This is the result of efforts in favour of trade liberalization made either through the multilateral approach of the GATT and later of the W'TO or through bilateral agreements of

\footnotetext{
* Honorary Professor of Economics at University Paris-Dauphine, former president of the Mont Pelerin Society.
} 
liberalization - which are increasingly used by governments - or even regional integration policies, in particular in Europe. Furthermore, the development of techniques in the field of transportation or in the circulation of information has contributed to this internationalization. But these changes are not always well understood and well accepted. Thus, there are many people who consider globalization as detrimental since it is assumed that it destroys jobs in developed countries because of alleged competition from low-wage countries, but also because it is assumed that it could lead to a "standardization" of the lifestyles and even cultures (which some do not hesitate to call "Americanization"). We thus often hear that, given these supposed dangers, it is not normal that the globalization of economic activities is not framed by a "globalization" of economic policies, i.e. a coordination or even an harmonization of these policies. As we will see, this idea is based on a great error. But it is this idea which has often inspired the efforts towards international cooperation, for example during the meetings of the G20.

Now, insofar as such a cooperation seems presently difficult to develop, it is often suggested that regional economic integration is preferable to globalization because it allows to establish some "organized markets", i.e. actually regulated markets. But it is striking to note that most people - especially politicians - have an extremely blurred and ambiguous vision of integration. Its implementation is often considered as an absolute requirement and as the only way to solve most economic problems. But the ambiguity which exists in this area results in particular from the fact that European integration is for governments a great double-sided alibi: On the one hand they will claim for instance wrongly according to us - that being members of the eurozone prevents some countries from practising monetary policies or exchange rate policies which would allow them to solve their economic problems. But they will also claim that such or such problem cannot be solved without a "European solution", i.e. the development of common policies and centralized European decisions. This is why, given the vague and ambiguous ideas concerning economic integration (but also globalization), it is important to clarify the meaning of such phenomena and their scope. We will start by clarifying the meaning of freedom of 
trade and competition, then we underline that there are two radically opposed approaches to integration and we will discuss finally, as an illustration of the previously presented ideas, accomplishments or projects concerning taxation, regulations, monetary integration and banking union.

\section{Free trade: gains and concerns}

The benefits of free trade are so obvious that one can wonder why they are not universally recognized. Human beings, in fact, have this outstanding characteristic of being all different one from each other; different by their abilities, but also by their needs and targets. The usefulness of exchange between individuals comes from this diversity. Each of us would be perhaps able to live alone on an island like Robinson. But it is in the interest of everyone to specialize in the activities for which he is relatively fitter than others and to buy what he needs and what he is relatively less able to produce. This principle, sometimes called the principle of comparative advantage, is well known in the field of international economic theory since it was proposed by David Ricardo.

Actually the theory of international trade is nothing else than an application of the general theory of exchange and specialization among individuals in the case where these individuals are located in different national spaces. And this theory more generally is a logical consequence of the human rationality assumption: As far as an individual is able to specify his own targets, he is able to adapt his actions to these aims and, for instance, to assess to what extent he can have an interest in exchanging with others. Thus, if two individuals (or two groups of individuals) decide freely to trade, although they could decide not to do so, it is because they both draw an advantage from trading. Now, the fact that two traders are located in different national territories does not in any way change the fundamental fact that both earn from the exchange, which is an undisputable justification of the freedom to exchange.

The theory of international specialization - also called theory of comparative advantage - being the outcome of pure logic, cannot be challenged and it is one of the strongest and most undebatable elements of any economic theory. It should inspire all economic policy decisions 
and it should lead everyone to think that globalization is necessarily beneficial. The spread of protectionism around the world and through time proves that it is unhappily not the case. Only two reasons can explain such a situation: ignorance or interest.

Certainly, one cannot exclude that ignorance is often at the origin of protectionism, the one of the "men of the State" (politicians or bureaucrats) or of citizens who cannot know the cost of such a policy for them. And it is also striking that men and women who have learned the comparative advantage principle on the benches of the University are unable to draw concrete conclusions which should be the practical consequences of this principle. But one should probably look for the real explanation of the spread of protectionism in the efforts of politicians to meet the vested interests of some individuals or some specific categories of people. It is the result of the working of the "political market", i.e. of those processes by which politicians are trying to reach their own goals. As shown, in particular, by Mancur Olson (1966), in a democratic system politicians try to maximize the number of votes they receive during elections. It is then their interest to assign privileges that are easy to perceive and well targeted and, on the contrary, to ensure that the cost of these measures is diffuse and painless. Protectionism provides a perfect illustration of this idea: protecting by customs duties a particular activity, politicians attract sympathy from the corresponding business leaders and employees. The cost of this measure — in addition to the administrative cost of collecting customs duties - is expressed by the fact that the sale price of the corresponding goods is higher than it would be under free trade. But consumers are numerous, poorly informed, little organized, so that the cost of protection for them is diffuse and little perceptible. By multiplying special protectionist privileges, politicians satisfy their electoral constituencies.

In reverse, trade liberalization faces opposition from organized interest groups which had previously obtained protection ${ }^{1}$ and this is why it is difficult to implement, especially if one wants to liberalize gradually: When one starts the liberalization process, each producer is sensitive to the losses he has to bear because of liberalization, he is relatively less sensitive to the gains which can possibly be obtained subsequently thanks to the liberalization of exchanges - and the 
correspondg decrease in prices - for the goods he may buy.

From this point of view agreements to create a free trade area or a "common market" are efficient methods of liberalization. Being comprehensive, they allow to overcome the reluctance of sectoral interests: Even if some producers are opposed to the liberalization process, others find new export markets and consumers get a greatest variety of goods with lower prices. No government accepts easily to suppress or to reduce tariffs one after the other, since no producer would agree to be the first to bear the consequences of tariff liberalization. And similarly, no Government, probably, can accept a unilateral tariff removal, although it would necessarily imply an improvement in the well-being of its citizens! By entering into a multilateral and comprehensive liberalization process a government makes it more acceptable to producers, since some of them, at least, will benefit as exporters or buyers of imported goods. Although the losers and the winners are not necessarily the same, there may be therefore offsettings between gains and losses.

Thus, during the creation of the European common market, many producers feared to be dispossessed of their national markets by new European competitors. But the gains of the European common market have been sufficiently rapid and perceptible to elicit strong adherence to the liberalization process, so that a return to protectionism between European countries seems excluded.

\section{The benefits of competition}

Strangely enough, in this area it is the dominant approach to economic theory which is erroneous and which inspires questionable policies. It is well known under the name of "theory of pure and perfect competition". According to this theory, in order for pure and perfect competition to prevail it is necessary, among other things, that the production of a particular good be made by a large number of producers producing this good with the same techniques and under the same conditions of production. If it is not the case - for instance if there is a single producer, called a monopoly - it is assumed that there is a risk that, taking advantage of its "market power", this producer plunders buyers by imposing a higher price than the "competitive price". 
However, it is very strange that this theoretical approach should be exactly the opposite of what is assumed in the current language. Thus, one says that two athletes have to compete if either tries to do better than the other (and not to achieve the same performance). In fact, the world described by the theory of pure and perfect competition is a purely hypothetical world unrelated to human reality. To say that producers have to compete cannot mean that they seek to be identical but quite on the contrary, that they will try to sell better and cheaper goods than the others, so as to get a greater market share. But this can happen only to the extent that they are free, free to enter into a market and to decide on their production processes. Thus, for competition to exist, it is necessary and sufficient that there is freedom to enter into markets.

If this definition of competition is accepted - which logically should be - one discovers that it has many implications. It means, first of all, that one of the great merits of competition is precisely the fact that it constitutes an incentive to differentiate (and not to do like others). It induces each producer to be innovative and it allows this differentiation which is at the origin of the gains of trade, as we have seen. On the other hand, if a producer is very innovative - and encouraged to be by competition - he will get a $100 \%$ market share when he is the first to launch a new product.

Such a situation is considered as harmful by the traditional theory of pure and perfect competition, as well as by the so-called laws in favour of competition, inspired by this totally false theory, while this single producer-innovator, far from plundering buyers, instead brings them the benefits of innovation. In reality, the only harmful monopolies are those imposed by coercion - more precisely the legal coercion of States - and the laws against monopolies should tackle these State monopolies, whose existence is due to the prohibition of competition. But the approach to competition which we support - defined as the freedom to enter into a market - also provides irreplaceable analytical tools to assess the issue of economic integration, as we shall see now. However let us first stress that it helps understanding why the current idea - which we have previously recalled - according to which globalization may cause the "standardization" of the ways of life and cultures is questionable.

Globalization can indeed be defined by the generalization of 
competition all over the world. However, the increased competition, due to the removal of barriers to trade in goods and services, factors of production and ideas, normally encourages individuals to differentiate themselves from each other. Certainly, in some specific cases, it may appear that certain practices are more or less universally considered to be the best and are therefore adopted by a majority of people, but fundamentally globalization is a source of diversity.

\section{The two approaches to integration}

The liberalization of trade among the countries of the European Economic Community (EEC) had been rightly designed initially as the most important goal of the European integration process. For this reason, one mainly mentioned at that time the building of a "common market". The dismantling of protectionist barriers has been implemented and it has been successful, it has resulted in an increased competition between European producers. This initial phase of European integration has therefore allowed Europeans to take advantage of a double gain: one which comes from the specialization of activities thanks to trade and one which comes from the stimulation given to innovation thanks to a greater competition.

But gradually, a large skid has occurred in the process of integration. One has increasingly abandoned the concept of a common market, i.e. a competition space where the freedom to enter into markets prevails, to focus on common policies and harmonization. To be sure, the development of common policies started at the beginning of the process of European integration and some of them were also laid down in the Treaty of Rome, which created the EEC. But it is no less true that there has been a change in the relative importance of these orientations. From the creation of a large common market one has shifted to the development of common policies which increase continuously their scopes and targets.

Now, economic integration between countries is desirable insofar as it implies the possibility for markets to freely play their role, without any "artificial" interference on the part of national governments. But common policies are generally means to prevent free competition. Thus, the term "integration" can have two very different meanings: developing 
so-called integration policies has nothing to do and is even opposed to the integration of markets. European authorities have been very skilful in creating and maintaining confusions between the two meanings of the word. They have thus used a confused feeling of public opinion to which any agreement, any "harmonization" - this term evoking a kind of social harmony - correspond to social peace. Yet, to argue that a system - in particular a human system - is integrated does not mean that all its parts are identical, but simply that their interactions allow it to operate in a consistent way (or, one might say, "harmoniously"). For such a situation to occur each element has to be specialized in the activities best suited to the needs of others. It is competition - and the diversity which it involves - which constitutes the best way towards such a consistency.

To make clearer the distinction between the two meanings of the word "integration", another confusion should be highlighted, the one which exists between competition, on the one hand, and the harmonization of the conditions of competition, on the other hand. Competition involves freedom of choice, both for producers as for consumers. It does not involve, quite the contrary, that all producers should be placed in the same environment, that they should be subjected to the same "conditions of competition". Economic theory - in particular the theory of international specialization - brings us this fundamental lesson that producers of a good placed in different conditions have the responsibility to manage the factors of production, taking into account the specific constraints that they undergo, in order to make their products competitive. Thus, a Spanish producer of tomatoes and a Dutch producer of tomatoes use very different production techniques, because they are in a different environment, since the Spanish producer enjoys free sunshine, which is a most important element. But either uses different production techniques, so that with his greenhouses heated with natural gas the Dutch producer can compete with the Spanish producer. It would be patently absurd to ask in this case for a "harmonization of the conditions of competition", i.e., for instance, to oblige the Spanish producer to put tarps on his tomato seedling to ensure the equality of sunshine conditions between him and the Dutch producer. The important thing is to ensure the existence of competition, both at the level of the markets for final goods and at the level of the 
markets for factors of production.

We can thus perceive the fundamental deviation of European integration between the fifties and now. One began, rightly, with the desire to introduce more competition between European producers, and then one slipped little by little to an entirely different idea, namely the harmonization of the conditions of competition. This idea translates into looking, in all fields of activity, at common European policies and common interventionist regulations.

Thus, law is one of the elements of the producers and consumers' environment and it plays a fundamental role, in particular because it influences the determination of decision-making processes and of property rights. Therefore, producers subject to different legal systems are not under the same conditions to produce, which does not prevent them, again, to compete. However, there are two ways to possibly change this situation:

- One may seek, as one tries to do within the European Union, to "harmonize legislation" so that all producers operate under the same "conditions of competition";

- One may decide - which would be much better - to introduce competition in the market for law, each producer, each trader being free to choose the legal system of his choice. Choosing one's legal system, in fact, could be considered as the normal responsibility of an entrepreneur exactly in the same way as selecting a technique of production. We do know that firms can compete efficiently although they use very different production techniques. It is the same for legal systems. Is it not true in fact that international competition takes place between producers who are subject to different legal systems?

Obviously, there can be degrees in the competitive nature of the "market for law". One can imagine, for instance, that competition is limited because of an obligation imposed by states to citizens to choose only among legal systems developed by them. But real competition would go further, i.e. it would allow the free production of legal systems. However, politicians want, at least, to participate in the process of production of a new legal system. But, instead of leaving an option for citizens, at least between existing legal systems, they are looking at the 
production of a new legislation, a supranational European one or, at least, a European regulatory system. In each country, obviously, politicians are trying to obtain that this supranational legislation should be as close as possible to their national legislation. One thus enters into the process of international negotiations (i.e. actually inter-state negotiations).

It is therefore necessary to pay extreme attention to the pitfalls of language: one uses the same word - integration - to designate totally different things. Thus commercial integration in Europe consisted in developing competition in commodity markets. But one rapidly came to activities in which the intervention of the State was important or even exclusive. The meaning of the word "integration" then changed. The main official target was no more to increase competition, but only to change the relationships between the national monopolies which States had created or between the interventionist policies of these same States. Integration is then no more considered from the point of view of markets, but from the point of view of "common policies".

The word "integration" thus covers two different situations. In one case, it implies an increase of competition - it is the integration of markets; in the other case, it involves rather a lessening of competition as it aims at reducing through compulsory means the differentiation of activities.

The EEC was created for essentially political reasons. It was felt that nationalism was responsible for World War II and the founders of the EEC sincerely wished to avoid such events. The final objective was therefore to create a European nation. But the building of this nation is unfortunately based on the usual prejudices of our time, namely that economic problems dominate all others and that by transferring powers of economic decision-making to European institutions one can create this European nation. People think generally that economic "unification" leads to political unification. But the politicization of economic life can do nothing else than exacerbate conflicts, contrary to what the market can do. 


\section{Harmonization of economic policies}

As illustrations of the general analysis above, we shall consider now some important examples of European policies of harmonization, those relating to taxation and regulations, monetary integration and the banking union.

\section{The harmonization of taxes and regulations}

One of the most frequently mentioned topics concerning European economic integration is that of "harmonization" of taxation. It seems obvious to most of the commentators that the working of a European single market implies an "equalization of the conditions of competition" and, in particular, of taxation. However, as already noted, it is quite absurd to "harmonize the conditions of competition" in a free economy, so that all producers of a country or a geographic area can produce exactly under the same conditions, i.e. with exactly the same structure of costs. It is yet such absurdities which are implied by all the proposals to "harmonize the conditions of competition".

Which differences could exist, indeed, between the harmonization of the conditions of sunshine which we mentioned earlier in relation to the producers of tomatoes, and the harmonization of tranportation conditions or tax conditions ? Taxation is one of the elements of the environment of entrepreneurs, among many others, and the entrepreneurs must adapt to differences in climate, population, or corporate law. The harmonization of tax rates between countries has no more justification that the harmonization of any element of production costs. But, obviously, the governments of countries where taxation is particularly unfair and destructive fear tax competition from other countries and they are doing everything possible to "harmonize" tax systems - under the pretext of implementing fair conditions of competition - with the hope that harmonization will involve an alignment of other tax systems on their own system. But if a tax is confiscatory and stupid it will not be less confiscatory and stupid if it is harmonized, quite the contrary! Many European countries, unfortunately, are real tax hells, but instead of correcting their mistakes their governments fight against so-called "tax havens", including, of course, those which are outside the borders of the European Union, for 
instance Switzerland. It is regrettable that their bargaining power allows them to gradually win victories, so that tax competition (intra-European and extra-European) is reduced to the benefit of tax hells.

The same reasoning must be made with regard to laws and regulations. Thus, in a country like France where the labour market is "organised", meaning that it is enslaved by a multitude of regulatory and legislative texts that are paralyzing, complex and even often rather incomprehensible (which largely explains the importance of unemployment), one complains of an alleged "unfair competition"2 from more reasonable countries. But instead of correcting the pitfalls of this system, one calls for the harmonization of "social legislation" in Europe (or even, possibly, in the world).

\section{Monetary union}

From the beginning of the process of European integration, the monetary union has been considered one of the major targets of this process. Since one sought to develop a European super-nation and since in our time the power to create money is considered an attribute of national sovereignty, it became evident that the integration of Europe involved a single currency controlled by a single European Central Bank. This is probably one of the main reasons for the creation of the euro. But in this area, as in all others, we find the opposition between the two approaches to integration: the competition approach and the harmonization approach. Insofar as, in our time, one is convinced that money must be produced by a public monopoly, it was considered that monetary integration involved the creation of a European monetary monopoly. This implied, on the one hand, the creation of the European Central Bank (ECB) and, on the other hand, the obligation for citizens of countries belonging to the euro area to use the single currency, the euro.

However, as early as 1976, when arguing in favour of monetary competition Friedrich Hayek pointed out that the best way towards monetary integration in Europe was simply to allow the competition between European currencies (and even with other public or private currencies which could be created). Here we find a particular application of the idea already expressed, that integration should be interpreted not 
as a process of unification but, on the contrary, as a process of competition and therefore of diversification.

Certainly, it is more convenient in trade to use a single currency rather than multiple currencies. But this is not the essential problem. What Europeans will have gained if they end up one day with a single European currency of very low quality, i.e. an inflationary currency? What was unfortunate before the creation of the euro was not the absence of a European Central Bank, but the existence of national central banks, which enjoyed a monopoly for the creation of money in their respective territories. And to defend this monopoly and to continue a policy of excessive and destructive money creation, they used coercion thanks to legal tender laws and exchange controls. Why could it not to be the same someday with a European Central Bank endowed with a monopoly for money creation in the eurozone and able to resort to exchange controls and legal tender laws?

On the other hand, if there were several competing currencies, citizens could flee from the inflationary currencies and take refuge in the more stable currencies. Competition implies the freedom for citizens to use any currency. If it was the case, it may well happen that the market, i.e. the people who are concerned, select a currency (or several of them) as better than others, so that monetary union would be achieved. But it would be a gradual and spontaneous way to implement monetary unification and the possibility for citizens to use another potential currency, in case the one which they had selected were "bad", brought them a protection and imposed a limit on the power of money creation.

Before the creation of the euro, those who are called "proEuropeans" (but who are, in fact, only representatives of a centralizing and unifying conception of Europe) claimed that the single currency would provide higher growth and more stability in Europe. Obviously, we have seen that it was not the case. But oddly enough, a certain disaffection against the euro could be observed during the recent period when it was usual to mention a "crisis of the euro", in particular because of economic problems in Greece and in some other eurozone member countries.

It is, in fact, unjustified to speak of a crisis of the euro, as the issues involved were not monetary but budgetary problems. And it is not 
because a country like Greece is part of the eurozone that its public debt is a problem of the euro, in the same way as one would not mention a "dollar crisis" if a U.S. State had budget problems. But the fact that Greece is a member of the eurozone has been a pretext to argue that it should get the support of other countries and even that its problems should allow the European monetary policy to help solving the fiscal problem.

Then, the "pro-Europeans" also take the pretext of this so-called "crisis of the euro" to claim that these events have demonstrated that there is a need to coordinate the fiscal policies of European countries. The single currency thus becomes for them an instrument to achieve their dream of a "harmonized" and centralized Europe (perhaps pending a world government which would be the worst among the risks to the freedom of human beings...).

\section{Banking union}

The banking union project is also an outcome of the recent financial and economic crisis. It is a perfect example of the errors of interpretation of this crisis which are made very generally. In fact, one can hear frequently people saying that the crisis was the consequence of the behaviour of greedy bankers who took excessive risks in order to increase their profits and bonuses. In reality, as all the crises of the modern era, the latest crisis has been caused by the destabilizing monetary policies of central banks, in particular the Fed, as well as by the interventionist policies of States ${ }^{3}$. But the usual interpretation induces people to seek the implementation of a system to limit risk-taking by banks and to better manage its consequences.

Furthermore, as one considers in our time that the solution to any problem must be at the level of the European Union, one infers that the supervision of the banking system by governments must become a European activity, and the banking union project is assumed to allow it. Among other things, this project consists in implementing an alert system to identify all excessive risks taken by European banks. To do this an organization has already been created, the Single Supervisory Mechanism. As one might imagine, it will probably define standards and criteria which will be imposed to banks and which will be expected to 
detect risky banks. However, the fact that these standards and criteria are the same for all banks across Europe is not reassuring, quite the contrary, given the extreme diversity of specific situations. Risk assessment is certainly not an easy task, but it is at its best when it is done on a small scale. Thus, the manager of a bank branch has relatively better information than anyone else in the banking institution to assess the risks attached to each loan that he agrees to, because he knows the business or the household that borrows, he is able to follow the evolution of their activities and assess their projects. But the more one moves away from this base level, the more the appreciation of risk is difficult to perform. One then uses very general criteria or econometric models, whose reliability is necessarily low. As explained by Friedrich Hayek, it is not by centralizing information that one can improve the working of a system, but by best using pieces of information which are necessarily very scattered. To do this one should rely on the decisions of responsible persons, i.e. persons who bear the consequences of their decisions. And the best way to be responsible is to be the owner. This is why the best adjustment process one can imagine cannot come from the creation of a public - therefore irresponsible - and highly centralized organization, but from the working of capitalism (which, unhappily, has been greatly destroyed by an excess of taxation and regulation in most countries). Now, on the other hand, certain characteristics of the banking union also contribute to reduce responsible behaviour in the banking system. Such is the case of mechanisms for the pooling of risks which monetary authorities are implementing. They imply that a poorly managed bank which took too many risks will be saved thanks to the resources taken from other banks, creditors or States. Instead of relying on the responsibility of competitive capitalist bankers, one implements a centralized and irresponsible European system which could therefore increase economic instability. 


\section{Conclusion}

Governments, as the authorities of Brussels, have extraordinary means to influence opinion. It follows that, when speaking of Europe, people have in mind public authorities in Europe and not its citizens and their freedoms, thus turning away from what is the common heritage of Europeans: the discovery and defense of individual freedom.

The European integration process, as it develops, is filled with dangers. We cannot forget, from this point of view, the risk of an increased European interventionism and the risk of a new European protectionism, which would "justify" the myth according to which everything which is done on behalf of Europe is good, and according to which Euroopeans should protect themselves from the outside world.

More important than the process of European integration would be the implementation of a world common market. And it would be much more important to liberalize than to harmonize. Liberalization implies nothing else than a unilateral initiative, which a country could easily decide, without worrying about what its neighbours do. But the obsession with international negotiations makes one forget that liberalization is both necessary and easy.

There is no need to harmonize in order to be the best and it may be useful to refer to the example of what has been called the "four Asian dragons" (South Korea, Hong Kong, Singapore and Taïwan). They did not have a harmonised tax system, but low taxation and high savings (due, precisely, to their tax systems and their individual protection systems). They did not need an Asian single market, or a "Commission of the Asian Union". Their economic space has been the whole world. This is also the case of Switzerland, and one should strongly hope that it can maintain its specificity and that it will remain a relative space of freedom in a Europe and a world which are too politicized and too "harmonized", and which threaten its singularity. This Europe and this world do need the examples which can be given to them by some other countries and they need the competition between economic systems, which is still possible.

Advocates of individual freedom must therefore be vigilant. Their means are weak relatively to organized interests and the fantastic resources that States collect by coercion. But they also have an 
HSS, vol. V, no. 1 (2016): 13-29

incomparable force, the one which is given by the conviction that they satisfy the requirements of reason and the requirements of ethics. Can we expect that this strength of conviction will allow the competitive approach to integration to replace gradually the dominant approach, namely integration by centralization, harmonization and public interventionism?

${ }^{1}$ Moreover, the so-called theory of "effective protection" has shown that some producers who believe that they benefit from protection, have in reality to bear a negative protection, which means that they are put at a disadvantage in comparison with those who benefit from a positive protection.

${ }^{2}$ This usual term is in fact a contradiction: As competition means freedom to act, it cannot be "unfair". What is unfair is the set of arbitrary regulations which put a limit on this freedom to act.

${ }^{3}$ We demonstrate this statement in a precise way in our book (in French), Revenir au capitalisme pour éviter les crises, Paris: Odile Jacob, 2010.

\section{Biographical note}

Pascal Salin is a French economist, professor emeritus at the Universite ParisDauphine and a specialist in public finance and monetary economics. He is a former president of the Mont Pelerin Society (1994 to 1996). Salin has been a consultant for the International Monetary Fund, the United Nations, the Food and Agriculture Organization, and the Harvard Institute for International Development. Mathieu Laine and Jörg Guido Hülsmann co-edited a festschrift in honor of Salin in 2006. He was made Chevalier de la Légion d'bonneur and Chevalier des Arts et des Lettres, as well as Officier des Palmes Académiques. He was awarded the Prix renaissance de l'économie in 1986. 